two groups (NCPAP, HFNC). During the study, those on HFNC had more normal examination of nasal mucosa $(\mathrm{P}<0.0001)$. According to neonatal nurses opinions, application of HFNC was easier than NCPAP for neonates $(\mathrm{P}<0.0001)$.

Conclusions HFNC is as effective as NCPAP in the management of RDS in premature neonates more than 30 gestational weeks. In addition, HFNC performed easier than NCPAP with maintaining a normal nasal mucosa.

\section{EARLY DETECTION OF NEONATAL RESPIRATORY DECOMPENSATION LEADING TO INTUBATION USING PREDICTIVE MONITORING}

doi:10.1136/archdischild-2012-302724.0394

${ }^{1} \mathrm{MT}$ Clark, ${ }^{2} \mathrm{BD}$ Vergales, 'DE Lake, ${ }^{2} \mathrm{KD}$ Fairchild, ${ }^{2} \mathrm{AO}$ PagetBrown, ${ }^{2} \mathrm{~A}$ Bowe, ${ }^{2} \mathrm{~J}$ Kattwinkel, 'JR Moorman. 'Internal Medicine; ${ }^{2}$ Pediatrics, University of Virginia, Charlottesville, VA, USA

Aims Very low birth weight (VLBW $<1500$ grams) infants in the Neonatal Intensive Care Unit (NICU) are at risk for respiratory deterioration requiring endotracheal intubation and mechanical ventilation, with associated morbidities. Methods for predicting impending respiratory failure are needed, as timely non-invasive treatments might avert severe deterioration and the need to intubate.

Our aim was to develop a predictive statistical model for continuous analysis of cardiorespiratory waveforms and vital signs to predict respiratory failure requiring intubation in VLBW infants.

Methods We collected continuous cardiorespiratory and demographic data, and types and times of respiratory support on all VLBW infants admitted to the University of Virginia NICU from January 2009-June 2011. We identified non-elective intubations that were followed by mechanical ventilation for at least $12 \mathrm{~h}$. Over 25 physiological measures were tested, and a multivariate logistic regression model was developed to estimate the relative risk of urgent intubation in the next 24 hours.

Results Of 287 VLBW infants admitted, 96 urgent intubations in which there were at least $12 \mathrm{~h}$ of waveform data occurred in 51 patients. The final model had ROC area 0.84 and employed oxygen saturation and its cross-correlation with heart rate, cross-correlation of heart and respiratory rates, and apnea burden. Inspection showed rising risk of intubation over the 12 to 24 hours prior to the event. Conclusion Predictive monitoring of cardiorespiratory waveform patterns and vital signs can detect incipient respiratory failure as much as $24 \mathrm{~h}$ prior to urgent intubation.

\begin{tabular}{|l|l}
\hline 395 & NASAL INTERMITTENT MANDATORY VENTILATION \\
VERSUS NASAL CONTINUOUS POSITIVE AIRWAY \\
PRESSURE FOR TRANSIENT TACHYPNEA OF THE \\
NEWBORN: A RANDOMIZED PROSPECTIVE STUDY
\end{tabular}

doi:10.1136/archdischild-2012-302724.0395

'G Demirel, 'N Uras, 'IH Celik, 'FE Canpolat, 1,2U Dilmen. 'Neonatology, Zekai Tahir Burak Maternity and Teaching Hospital; ${ }^{2}$ Pediatrics, Yildirim Beyazıt University, Faculty of Medicine, Ankara, Turkey

Background and Aims Nasal continuous positive airway pressure (NCPAP) is widely used for the treatment of transient tachypnea of the newborn (TTN). In this study we hypothesized that the use of nasal intermittent mandatory ventilation (NIMV) may be well tolerated in TTN and we aimed to evaluate its efficacy in reducing the duration of respiratory distress compared with NCPAP in TTN.

Methods This prospective, unblinded, randomized, controlled clinical trial was conducted in 40 eligible infants with a gestational age $\geq 37$ weeks, and birth weight $\geq 2000 \mathrm{~g}$ who were hospitalized for TTN. Infants were randomized to either nonsynchronized NIMV $(n=20)$ or NCPAP $(n=20)$. The primary end point was the reduction of the duration of respiratory distress. Secondary end points were the duration and level of oxygen supplementation, the incidence of complications such as pneumothorax, pneumonia and respiratory failure requiring entubation.

Results There was no significant difference in the demographic features of the groups. There were no significant difference in the duration of respiratory support $(28.0 \pm 19.2 \mathrm{~h}$ vs $32.2 \pm 23.3 \mathrm{~h}$, $\mathrm{p}=0.231), \mathrm{O}_{2}$ therapy $(31.2 \pm 15.6 \mathrm{~h}$ vs $29.0 \pm 19.3 \mathrm{~h}, \mathrm{p}=0.187)$, duration of TTN $(67.6 \pm 36.5 \mathrm{~h}$ vs $63.3 \pm 39.1 \mathrm{~h}, \mathrm{p}=0.480)$ and hospitalization $(6.2 \pm 2.6 \mathrm{~d}$ vs $5.4 \pm 2.0 \mathrm{~d}, \mathrm{p}=0.330)$ between the groups. The rate of complications were not significantly different between the groups.

Conclusions Our study indicates that NIMV is well tolerated and as effective as NCPAP in the treatment of TTN.

\section{CURRENT PRACTICE REGARDING THE USE OF HUMIDIFIED HIGH FLOW NASAL CANNULAE (HHFNC) IN UK NEONATAL UNITS}

doi:10.1136/archdischild-2012-302724.0396

'P Desai, 'S Shetty, ${ }^{2} \mathrm{~N}$ Singh, ${ }^{1} \mathrm{~N}$ Kennea. ${ }^{1} 1{ }^{\text {St }}$ George's Hospital NHS Trust; ${ }^{2}$ Ealing Hospital NHS Trust, London, UK

Background Neonatal respiratory support using high flows of heated/humidified gas via nasal cannulae has gained acceptance in the UK despite limited evidence of efficacy and safety. HHFNC seems well tolerated with little reported airway trauma, reduced noise exposure, and easier nursing than NCPAP.

Aim To determine current practices in terms of usage, types of devices and weaning regimes of HHFNC.

Methods All 203 neonatal units across UK were contacted and a structured telephone questionnaire completed.

Results All 203 UK neonatal units (100\%) completed the survey, 113 neonatal units $(56 \%)$ use some form of HHFNC. There is more HHFNC use in level 3 neonatal intensive care units (Table 1).

Of the units using HHFNC, 47 (42\%) use HHFNC either as standard respiratory support following extubation or following NCPAP with the remainder (58\%) using NCPAP initially and then HHFNC. The majority $(60 \%)$ of units commenced HHFNC at 8 litres per minute (lpm) flow and $30 \%$ of units at $5-61 \mathrm{pm}$ and reduced in $0.5-11 \mathrm{pm}$ steps to wean. Most units weaned off HHFNC once the flow rate was $2-31 \mathrm{pm}$.

Conclusion This is a large UK study evaluating the use of HHFNC. This survey demonstrates increasing use of HHFNC and wide variations in methods of use and weaning parameters. There is a need for further research in this area.

Abstract 396 Table 1 Use of HHFNC according to Level of neonatal units

\begin{tabular}{llll}
\hline & $\begin{array}{l}\text { Special care baby } \\
\text { units (level 1) }\end{array}$ & $\begin{array}{l}\text { Local neonatal } \\
\text { units (level 2) }\end{array}$ & $\begin{array}{l}\text { Neonatal intensive } \\
\text { care units(level 3) }\end{array}$ \\
\hline HHFNC used (UK) & $12 / 53(23 \%)$ & $60 / 92(64 \%)$ & $41 / 58(70 \%)$ \\
HHFNC used \% England/ & $28 \% / 0 \% / 0 \% / 0 \%$ & $64 \% / 50 \% / 100 \% / 50 \%$ & $71 \% / 50 \% / 83 \% / 100 \%$ \\
$\begin{array}{l}\text { Wales/Scotland/Northern } \\
\text { Ireland }\end{array}$ & & & \\
\hline
\end{tabular}

397 HIGH FLOW NASAL CANNULAE CAUSE LESS NASAL TRAUMA COMPARED TO NASAL CONTINUOUS POSITIVE AIRWAY PRESSURE IN PRETERM INFANTS

doi:10.1136/archdischild-2012-302724.0397

C Collins. Neonatal Medicine, Mercy Hospital for Women, Melbourne, VIC, Australia

Background Nasal continuous positive airways pressure (NCPAP) facilitates extubation but can cause nasal trauma which ever device is used. The burden of nasal trauma is poorly defined in the literature. Nasal trauma often occurs in the smallest infants who require 